J. Biosoc. Sci., (2016) 48, S116-S147 (C) Cambridge University Press, 2016. This is an Open Access article, distributed under the terms of the Creative Commons Attribution licence (http:// creativecommons.org/licenses/by/4.0/), which permits unrestricted re-use, distribution, and reproduction in any medium, provided the original work is properly cited.

doi:10.1017/S0021932016000171

\title{
DEWORMING DELUSIONS? MASS DRUG ADMINISTRATION IN EAST AFRICAN SCHOOLS
}

\author{
TIM ALLEN ${ }^{* 1}$ AND MELISSA PARKER $\dagger$ \\ * Department of International Development, London School of Economics, UK and \\ $\dagger$ Department of Global Health and Development, London School of Hygiene and \\ Tropical Medicine, UK
}

\begin{abstract}
Summary. Recent debates about deworming school-aged children in East Africa have been described as the 'Worm Wars'. The stakes are high. Deworming has become one of the top priorities in the fight against infectious diseases. Staff at the World Health Organization, the Gates Foundation and the World Bank (among other institutions) have endorsed the approach, and school-based treatments are a key component of large-scale mass drug administration programmes. Drawing on field research in Uganda and Tanzania, and engaging with both biological and social evidence, this article shows that assertions about the effects of school-based deworming are over-optimistic. The results of a much-cited study on deworming Kenyan school children, which has been used to promote the intervention, are flawed, and a systematic review of randomized controlled trials demonstrates that deworming is unlikely to improve overall public health. Also, confusions arise by applying the term deworming to a variety of very different helminth infections and to different treatment regimes, while local-level research in schools reveals that drug coverage usually falls below target levels. In most places where data exist, infection levels remain disappointingly high. Without indefinite free deworming, any declines in endemicity are likely to be reversed. Moreover, there are social problems arising from mass drug administration that have generally been ignored. Notably, there are serious ethical and practical issues arising from the widespread practice of giving tablets to children without actively consulting parents. There is no doubt that curative therapy for children infected with debilitating parasitic infections is appropriate, but overly positive evaluations of indiscriminate deworming are counter-productive.
\end{abstract}

${ }^{1}$ Corresponding author. Email: T.Allen@LSE.ac.uk 


\section{Introduction: Worm Wars}

Deworming school-aged children has been identified as one of the five top priorities in the fight against infectious disease. According to the Copenhagen Consensus Centre, 'spending $\$ 300$ million would mean about 300 million children could be dewormed, with benefits in economic terms ten times higher than the costs' (Copenhagen Consensus, 2013). The Centre is a think tank that includes Nobel Prize winners, and researches the 'smartest solutions for the world's biggest problems'. Other influential organizations have presented similar arguments. For example, Don Bundy, representing the World Bank, endorsed the work of 'Deworm the World', a project co-founded by Michael Kremer, the Gates Professor of Economics at Harvard. In 2011, he reported that: 'while deworming has proven to be one of the most cost-effective interventions to get children into school, promising new research suggests that deworming children can also result in many long-term benefits, including higher wages, healthier individuals and stronger communities ... Findings of a long-term impact study in Kenya showed participants who were dewormed as children had higher wages, fewer sick days, more work hours and higher-level occupations. Even better, the treatment resulted in benefits to the health of external populations, including untreated children, younger siblings and neighboring communities' (Bundy, 2011).

The term 'deworming' is commonly used to refer to treatment with the drug albendazole, for a range of intestinal parasites, such as roundworm (Ascaris lumbricoides), whipworm (Trichuris trichiura) and hookworm (Necator americanus and Ancylostoma duodenale). This group of parasites is referred to as soil-transmitted helminths. However, the term is not always used consistently. It can relate to the treatment of other helminth infections too, notably schistosomiasis ( $S$. mansoni and $S$. haematobium), onchocerciasis and lymphatic filariasis. Schistosomiasis is treated with praziquantel; onchocerciasis is treated with ivermectin; and lymphatic filariasis is treated with a combination of albendazole and either DEC (diethylcarbamazine citrate) or ivermectin.

Soil-transmitted helminthiases, schistosomiaisis onchocerciasis and lymphatic filariasis are among the 'core' neglected tropical diseases (NTDs) on the World Health Organization's list to be controlled, or even eliminated, primarily by mass drug administration (WHO, 2016). According to the Gates Foundation, this is the largest public health programme ever attempted (Gates Foundation, 2009, 2014). The relevant tablets are being donated in huge quantities by leading pharmaceutical companies, and free preventive chemotherapy is being rolled out on a massive scale, with countries in Africa setting the pace. The approach requires treatment, without individual testing, of entire populations in endemic locations, at regular intervals, with the intention of reducing both the prevalence and intensity of infection. Deworming school children is one component, but a very important one. There is a history of successfully deworming school children in high-income countries, including the USA and Japan, and it is expected that benefits will accrue if similar approaches are taken in resource-poor settings (Bundy \& de Silva, 1998). In addition, some very positive assessments of deworming in selected Kenyan schools since the late 1990s have suggested that upscaling treatment in Africa and elsewhere is both viable and effective.

However, not everyone agrees. A growing number of researchers have argued that the existing data are partial and sometimes inaccurate, that the school-based distributions may be ineffective and that the whole project of preventive chemotherapy needs rethinking. 
While the tablets can have positive effects for many of those who take them, there are both biological and social reasons why current strategies are unlikely to lead to the anticipated outcomes. Making such points has provoked what has been called the 'Worm Wars' (Evans, 2015). The stakes are high. Investments in African school-based mass drug administration have been substantial and much is expected from them. Moreover, the reputations of leading analysts and institutions are on the line.

Drawing upon a wide range of research carried out mainly in East Africa, this article comments on these debates. In places, it also draws on findings from ethnographic research carried out, or supervised, on deworming adults and children since 2005 in more than 100 villages, spread out across Uganda and Tanzania. Some of the results have already been published (Parker et al., 2008, 2012; Allen \& Parker, 2012; Parker \& Allen, 2011, 2013a). Here, insights and data specifically on the school-based distributions are added. Overall, the available evidence from East Africa indicates that sustainable control of these NTDs, let alone their elimination, by means of mass drug administration in schools and villages is unlikely. This leads to a curiously controversial conclusion: the only way forward is to give priority to credible biosocial analyses of what is actually occurring in order to develop more adequately holistic, and locally relevant, responses.

\section{Why deworm?}

Given the emphasis that has been placed on deworming in African schools, the evidence that it is an effective public health strategy is surprisingly weak. The most-referenced scholarly publication on the topic is by Michael Kremer and Edward Miguel (Kremer \& Miguel, 2004). Irrespective of its conclusions, this article has been admired by economists for its insightful and innovative application of econometrics. It is published in one of the highest ranked economics journals and the authors are eminent scholars based at prestigious institutions. Analysing data collected from primary schools in Kenya's Busia County during 1998 and 1999, their results indicated a reduction in absenteeism of $25 \%$, following deworming with albendazole at 6 -month intervals for soil-transmitted helminths and with praziquantel once a year for intestinal schistosomiasis (S. mansoni). They did not find an improvement in academic attainment, but they did find that deworming 'substantially improved health and school participation among untreated children in both treatment schools and neighbouring schools' (Miguel \& Kremer, 2004, p. 159). They argued that the 'externality effects' (the indirect benefits to children in neighbouring schools) were large enough in themselves to justify fully subsidizing deworming, and the article was used to make the case for preventive chemotherapy to be provided to all school children living in areas where helminth infections are endemic.

With so many governments committed to providing universal primary education, deworming seemed like a unique opportunity to develop a straightforward and cost-effective vertical intervention. Teachers were thus tasked with delivering free treatment to their pupils, and ideally educating them about the prevention of these diseases. In fact, the WHO had already committed itself to school-based deworming for schistosomiasis and soil-transmitted helminths in 2001, with the World Health Assembly Resolution 54.19 endorsing the goal of treating at least $75 \%$ of school-age children in endemic areas by 2010. Also, in 2003, the WHO had proclaimed that deworming 
children was effective, easy and cheap in a pamphlet called 'School Deworming at a Glance' (WHO, 2003). As evidence, the publication cited a working-paper version of the Miguel and Kremer article on Kenya. In addition, it highlighted work describing positive long-term economic consequences of eradicating hookworm disease in the American South during the 1910s by Bleakley - although this was the result of a broadbased public health campaign, rather than one focused specifically on deworming in schools (Bleakley, 2002).

More directly relevant to the case presented in the WHO pamphlet were references to two studies on deworming by the Partnership for Child Development (PCD, 1999, 2002). The first of these, based on research in the late 1990s, had assessed the costs of distributing drugs for the treatment of schistosomiasis and soil-transmitted helminthiases as an integral part of school health programmes. The programmes had reportedly reached 80,442 pupils in 577 schools in Volta Region, Ghana, and 109,099 pupils in 350 schools in Tanga Region, Tanzania. The researchers concluded that delivering treatment in schools offered significant savings in delivery costs. It was calculated that the basic cost of delivering a universal, standard, school-based health intervention might be as low as US\$0.03 per child treated, but that a slight increase in the complexity of delivery would have a significant impact on the cost of intervention. For the second PCD study (2002), a variety of tests were given to 272 children in Tanzania who were infected with urinary schistosomiasis (S. haematobium) and/or hookworm, and to 117 children who were free from parasitic infections. Previous studies had indicated that these two heminth infections might impair cognitive function but, where such an impairment had been described, it was not clear if this was caused by iron deficiency anaemia, poorer growth rates, general undernutrition, socioeconomic status or a range of other factors, such as malaria parasite density. An aim of the PCD research was to improve on previous work by including a large sample of children and by assessing a more comprehensive set of potentially confounding variables. It actually produced more ambiguous results than those suggested by the WHO. It found that 'children with a heavy $S$. haematobium infection had significantly lower scores than uninfected children on two tests of verbal short-term memory and two reaction time tasks. In one of these tests the effect was greatest for children with poor nutritional status'. However, the study also found that there 'was no association between infection and educational achievement, nor between moderate infection with either species of helminth and performance on the cognitive tests' (PCD, 2002, p. 104).

Drawing on these findings, the WHO's recommendations in 'School Deworming at a Glance' included: 'Don't waste time and resources trying to examine each school or child. Deworming drugs are safe and can be given to uninfected children. No individual diagnosis, or assessment of each school is needed' (WHO, 2003). In November the following year, the approach was further elaborated at a meeting convened by the WHO in Geneva for a group called Partners for Parasite Control (PPC). The participants produced a report entitled 'Deworming for Health and Development' (WHO, 2005a). Once again, citing Miguel and Kremer's work in Kenyan schools, and highlighting on-going deworming programmes in East Africa, the report explained that the key intervention adopted by the PPC is morbidity control based on the delivery of regular anthelminthic treatment to high-risk groups, including school-aged children, in endemic countries. Reiterating the WHO's target of regular treatment of at least $75 \%$ of all 
school-aged children at risk of morbidity from schistosomiasis and soil-transmitted helminth infections by 2010, the report argued it was feasible. According to one of the participating groups at the PPC meeting, the Schistosomiasis Control Initiative (SCI): 'In Uganda, 1.4 million school-age children and adults in highly endemic areas have been treated and a reduction in the prevalence and intensity of schistosomiasis and soil-transmitted helminthiasis has been demonstrated. In addition, an increase in knowledge of schistosomiasis and reduction in pathology have been achieved' (WHO, 2005a, p. 16). The SCI additionally noted that Tanzania had decreed a National Schistosomiasis Day, targeting over 4 million school-aged children.

The SCI's assessment was partly based on preliminary results from a longitudinal survey assessing the effects of deworming with albendazole and praziquantel on 1871 randomly selected school children from 37 schools in eight districts across Uganda (Kabatereine et al., 2007). The children were assessed at three points between 2003 and 2004. Significant declines were noted in the prevalence and intensity of infection with $S$. mansoni and soil-transmitted helminths following multiple rounds of treatment. There was also a reduction in the prevalence of anaemia. The study did not directly address educational aspects, but the data on anaemia could be taken to imply that the children had more energy. It concluded that anthelminthic treatment of school children, delivered as part of a national helminth control programme, can decrease infection and morbidity among school children, and that the experience of the Uganda national control programme confirms the potential of helminth control demonstrated through pilot programmes (Kabatereine et al., 2007). Positive results were additionally reported from another study in Uganda by the same authors, again based on cohorts of children, but including cohorts of adults and cohorts of newly recruited 6-year-olds who had never previously received treatment (Zhang et al., 2007).

By the time these findings were published, the WHO had already released another pamphlet, stating that available evidence had confirmed deworming will help meet the Millennium Development Goals (WHO, 2005b). Miguel and Kremer's Kenyan findings were cited as showing that the strategy 'boosts the prospects of school-age children to earn their way out of poverty'. Building on this, the WHO initiated what was described as a 'ground-breaking drive against diseases with preventative drugs'. At the launch, in October 2006, David Molyneux, one its most prominent proponents, again evoked the Miguel and Kremer results: 'You can have a hell of an impact on the health of children and protect future generations through better school attendance and future growth for a cost that is pathetic' (Jack, 2006). Mass drug administration has subsequently become a global undertaking, with an integral component being deworming in schools. In 2007, the WHO announced a 'Global plan to combat neglected tropical diseases 2008-2015', setting benchmarks for integrated treatment packages with multiple drugs (WHO, 2007), and, in 2010, the WHO released its first major report on NTDs (WHO, 2010). The latter claimed that, by 2008, preventive chemotherapy had reached nearly 670 million people, and on the treatment of children, it noted that: '... control programmes in endemic countries have demonstrated that the benefits of regular deworming are not limited to reducing direct morbidity. School attendance, school results and productivity improve' (WHO, 2010, p. 139). Specifically, with reference to Kenya, it reported that on the basis of the estimated rate of return to education, deworming is likely to increase the net present value of wages by more than US\$40 per treated person (WHO, 2010, p. 16). 
A few months later, the WHO issued a 'roadmap' on NTDs, setting out a detailed set of targets (WHO, 2011). For soil-transmitted helminths, 75\% of pre-school and schoolaged children in need of treatment are to be regularly treated in all affected countries by 2020, and for schistosomiasis, elimination is to be achieved in selected African countries. For some diseases, such as lymphatic filariasis, the benchmark was set even higher at 'global elimination'. In January 2012, the roadmap set the agenda for a meeting in London of donors, pharmaceutical companies, governments and other interested parties. Together they agreed the London Declaration on NTDs, committing themselves to the WHO targets, and to supporting a further surge in funding and provision of free medications (London Declaration on NTDs, 2012).

Since 2012, millions of tablets are reported to have been used to treat enormous numbers of people. For example, in 2014, the Kenya National School-Based Deworming Programme stated that it had treated at least 6.4 million children in more than 15,000 schools (KNSDP, 2014). As with deworming programmes elsewhere, there is an assumption that the benefits will be significant. However, more critical voices have come to the fore. In particular, concerns have focused on the reliability of Miguel and Kremer's seminal article (Miguel \& Kremer, 2004). For advocates of mass deworming, their work on Kenyan schools had taken on a quality of received wisdom. So it is, perhaps, unsurprising that a storm of controversy has arisen from a questioning of the results.

\section{Deworming debunked?}

As part of a wider programme of re-analysing influential studies in international development, the International Initiative for Impact Evaluation commissioned an independent group of epidemiologists to re-analyse Miguel and Kremer's 2004 study. The original data set was used, because Miguel and Kremer had made it publicly available in the interests of transparency. Ostensibly, the purpose was to make their analysis more comprehensible. It was noted that the 2004 paper itself was 'based on econometric approaches and used a language and format that would be unfamiliar to many health care workers' (Garner et al., 2015, p. 1). The findings of the re-analysis were published in a pair of linked papers (Aiken et al., 2015; Davey et al., 2015).

Aiken et al. (2015) highlighted mistakes in the coding of data and in the analytical approach employed in Miguel and Kremer's article, making some of the central findings false or misleading. In particular, the much cited $25 \%$ reduction in school absenteeism, as originally calculated, was not correct. After correction of coding errors, Aiken et al. observed, '...there was little evidence of an indirect effect on school attendance among children in schools close to intervention schools. Combining these effects gave a total increase in attendance of $3.9 \%$ among treated children, which was no longer statistically significant' (Aiken et al., 2015, p. 1572). Meanwhile, Davey et al. (2015) noted a substantial amount of missing data, and that findings relating to absenteeism differed according to choice of regression model. They also showed that there were correlations between the number of observations made in each school and reported attendance. In other words, the process of doing observations may have affected results, and Miguel and Kremer's findings might not have been representative of what happened at schools where observations did not occur. 
In response, Miguel and Kremer argued that Aiken, Davey and their colleagues made three 'non-standard and highly questionable analytical choices': (1) they divided the data set into two separate one-year experiments, thereby reducing statistical power and making it unlikely that estimates would be statistically significant; (2) they added unnecessary 'noise' by defining the deworming treatment measure to include periods before drug treatment had been administered; and (3) they weighted every individual child equally, rather than each school equally, such that a child in a large school had much less weight in the analysis than a child in a small school. According to Miguel and Kremer, it is only when two of these choices are made simultaneously 'that deworming impact estimates on school attendance are not statistically significant'. Miguel and Kremer acknowledged that they themselves had made 'minor errors', and accepted that the positive externality effects they had previously proposed needed to be revised, but maintained that this in no way negated the positive externality effects within schools or across schools within a $3 \mathrm{~km}$ radius (Kremer \& Miguel, 2015; Hicks et al., 2015).

Numerous economists and public health analysts have entered the fray, and there has been considerable media interest (e.g. Boseley, 2015; BBC, 2015; Hawkes, 2015). In general, it would be fair to say that much of the initial discussion consisted of journalists focusing on the apparent debunking of a famous economics paper, and economists attempting to assert the credibility of their discipline (and two of its leading scholars) by disparaging the questions being raised, as well as the motivations and academic status of those asking them. Most of the economists took their cue from Miguel and Kremer's own published reactions. The authors of the re-analysis papers have been accused of just wanting to be noticed by generating controversy (Evidence Action, 2015), and it has been asserted that their findings only eliminate the impact of deworming on school attendance 'if you torture the data' (Gertler, 2015).

There have, however, been some less partisan commentators. Perhaps the most balanced review of the debate from an 'economics' perspective is that by Macartan Humphreys, Professor of Political Science at Columbia University (Humphreys, 2015). He compellingly confirms that the widely cited $25 \%$ drop in school absenteeism as a result of deworming reported in Miguel and Kremer's 2004 paper is a miscalculation. A corrected analysis of their data, using the same estimator as in the original article, suggests that deworming did not have a significant impact on school absenteeism, and that evidence of positive externality effects on either infection or school attendance is questionable (and insignificant in the second year of treatment). Furthermore, when flaws in the study design are taken into account, it is quite possible that any recorded increase in school attendance was not an effect of the medication itself. Also, there is no evidence that deworming had a significant effect on anaemia and intermediate health outcomes. In sum, Humphries both confirms and elaborates the key conclusions of the replication papers.

One of Humphreys' colleagues at Columbia, the influential blogging economist, Chris Blattman, similarly acknowledges errors in the 2004 paper (although he does his best to find more remaining value in it). In a blog called 'Things I learned in the trenches of the worm wars', he has helpfully tried to shift the focus, making the following observation: 'To me, the real tragedy is that, 18 years after the Kenya deworming experiment (which was not even a real experiment) we do not have large-scale, randomized, multi-country, long-term evidence on the health, education, and labour 
market impacts of deworming medicine. This is not some schmuck cause. This is touted as one of the most promising development interventions in human history' (Blattman, 2015).

$\mathrm{He}$ is largely right. The Kenyan deworming experiment analysed by Miguel and Kremer was not a randomized controlled trial as is normally understood. Instead, they used the staged introduction of school-based deworming to construct something approximate to such a trial (in a stepped-wedge design). Blattman is also correct to say that we do not have the kind of high-quality evidence he alludes to. In the past 10 years, millions of children have apparently been dewormed in the manner Miguel and Kremer described. Their 'non-experiment' has been attempted on a huge scale, and not only in Kenya. In this context, it seems reasonable to suppose that part of the reason why no large-scale and systematic investigation of the effects has been published is that there has been a perception that deworming is self-evidently a useful thing to do, and that its benefits are proven beyond doubt. It is certainly the case that mass drug administration has become imbued with normative assumptions, linked to moral claims about assisting the most impoverished. As Allotey et al. has put it, "under the guise of a "pro-poor" strategy and a vaccine against poverty, it marks a resurgence of a medical and technological "magical bullet"...' (Allotey et al., 2010, p. e32).

Nevertheless, it is misleading to suppose that there have been no evaluations at all. There have been many, and the 'Worm Wars' have been on-going for quite some time. Recent attacks on Aiken, Davey and their colleagues are just the latest round in hostilities. For years, those raising concerns about deworming have been castigated, often in moral terms. They have been accused of being 'unethical' and violating 'the fundamental right to health'; of making arguments that 'would commit many thousands of people...to a life of misery', and that are 'disrespectful to endemic countries...unethical and grossly negligent' (Tchuente et al., 2006; Molyneux \& Malecela, 2011, p. e234). Polarized exchanges have occurred in The Lancet and the UK Parliament, which were summarized in media accounts, notably a lead article in The Times Higher Education (Allen \& Parker, 2012; Molyneux et al., 2012; Meheus et al., 2012; Reisz, 2013). The apparent disinterest in this other work and the debates associated with it is a peculiar aspect of many recent commentaries. It is perhaps symptomatic of unhelpful disciplinary silos, although Miguel and Kremer's own more recent research has tended to be ignored too. For some analysts, it seems, the issue at hand is the divergent interpretations of data published in an old paper, rather than the actual effects of deworming policies on African children and their relatives.

\section{Deeper deworming doubts}

Doubts were, in fact, expressed about large-scale deworming right from the start. For example, Dickson et al. (2000) found a paucity of evidence that routine treatment of children had beneficial effects where helminths are common, and Bruno Gryseels (Director of the Institute of Tropical Medicine in Antwerp) observed that indiscriminate drug treatment was based on poor science and poor public health practice (Geerts \& Gryseels, 2000; Gryseels, 2006). Gryseels outlined his objections succinctly in a letter to the Financial Times in 2006. Essentially, he argued that large-scale anti-helminthic mass treatment would drain resources from already overburdened and understaffed health 
systems, and would inevitably promote the emergence of parasitic drug resistance. He also noted that mass drug administration raises ethical concerns: 'The safety of several drug combinations has not yet been tested in rigorous clinical trials, while treatment does not benefit non-infected individuals in any way and has no altruistic effect. It is unlikely that such practices would be accepted in a Western society' (Gryseels, 2006). These are all important points. They were dismissed by leading African deworming protagonists in a published reply (Tchuente et al., 2006), but they cannot just be wished away.

In terms of whether deworming overwhelms health systems, this is difficult to assess in a systematic way. A similar criticism was made in the past of UNICEF's selective primary health care campaigns of the 1980s. Those were also based on morally loaded and vertically delivered medical interventions, which tended to by-pass or co-opt national health programmes. The simplistic emphasis on immunization coverage and distribution of oral rehydration salts has become paradigmatic of the inappropriate 'magic bullet' approach to fixing poverty that Allotey and her colleagues alluded to in the article cited above (Allotey et al., 2010). In common with the current mass drug treatment programmes, there was a massive increase in funding and resources focused on specific diseases, combined with an emphasis on achieving targets. Despite claims to the contrary, there was minimal local ownership and, in practice, broader health priorities were set aside (Parker \& Allen, 2014).

Several studies have described similar effects from the deworming campaigns. For example, Coulibaly et al. (2008) and Cavalli et al. (2010) have found that the additional burden of work placed on those rolling out mass treatment programmes in Mali adversely affected other essential activities, and thereby undermined already fragile health services. In private, African professionals working on NTD control tend to openly recognize the problem, but accept that there is no alternative if they want to secure global funding. In a carefully written paper, of which Kabatereine - the then Head of Vector Control in Uganda's Ministry of Health - was the lead author, it was observed that integration of mass drug administration inevitably puts an additional strain on existing systems, and may be detrimental (Kabatereine et al., 2010). He was more explicit in a published interview, criticizing the way in which USAID had set up an unsustainable parallel implementation structure in his country (Yamey, 2009).

With respect to the emergence of parasitic drug resistance, this is a matter of on-going discussion. It is a well-known and widely observed problem with other anti-infective medicines, notably some malaria treatments and most antibiotics. To the extent that this has been demonstrated to be a serious risk with deworming drugs, the evidence mostly relates to albendazole and ivermectin. Resistance to both drugs has been shown to be common when used widely for managing parasites in livestock (Geerts \& Gryseels, 2000; Waghorn, 2006). Also, declining effectiveness over time when used frequently in human populations has been observed by several scholars: for example, Albonico et al. (2004) and Bethony et al. (2006). It has also been observed that albendazole, in particular, can have remarkably different cure rates, ranging from $0 \%$ to $70 \%$ according to research findings from Ghana (Humphries et al., 2012). The biological factors behind these observations are being investigated and modelled, and there are doubtless a variety of causes. For example, by modelling the age profile of infection, Anderson et al. (2013) have shown that school-based deworming is less likely to have 
benefits for some infections than for others. However, the degree to which actual drug resistance in humans is a factor remains unclear. Nevertheless, the findings on cure rates are troubling.

Almost any organism will respond to a selective drug pressure by developing resistance over time, and it hard to see how a decline in helminth infections as a result of mass treatments with albendazole and ivermictin could be maintained without indefinite distributions, unless there is a reduction in the risks of re-infection. This has repeatedly been shown to be the case in the past. The prevalence of hookworm infection, for example, reached $80 \%$ of pre-treatment rates within 30-36 months in Papua New Guinea (Quinnel et al., 1993); the prevalence of T. trichiura infection reached $44 \%$ of pre-treatment rates within 17 months in Kuala Lumpur, Malaysia (Chan et al., 1994); and the prevalence of $A$. lumbricoides reached $55 \%$ of pre-treatment rates within 11 months at study sites in South India (Elkins et al., 1998). A recent study of deworming with albendazole in Kenya, discussed further below, underlines the problem. It shows that repeated rounds of treatment have a limited effect on the prevalence and intensity of infection with soil-transmitted helminths, unless the risk of re-infection is reduced. Unsurprisingly, better sanitation is important (Nikolay et al., 2015). There are also additional complications with long-term mass drug administration for soil-transmitted helminths, including the possibility of increasing the likelihood of developing allergies and autoimmune disorders (Elliot et al., 2011; Correale et al., 2011). Low-intensity helminth infections might actually be beneficial to human health, although the mechanisms by which this occurs remain unclear.

For praziquantel, matters are similarly ambiguous. In addition to Gryseels (Gryseels et al., 2001; Gryseels 2006), many biomedical researchers have highlighted drug resistance as a possibility (for example, Mahmoud \& Zerhouni, 2009; Gray et al., 2010; Utzinger et al., 2011; Humphries et al., 2012). Moreover, resistance can be experimentally induced, and praziquantel-tolerant schistosomes have been reported (Colley et al., 2014). There are reports, too, of treatment failing in field settings, although those failures are likely to be explained by praziquantel's inactivity on immature worms. Repeating treatment after 3-6 weeks could help deal with the problem, but it is not an approach that has (so far) been feasible for mass deworming campaigns. A related concern is that treatment with praziquantel might lead to susceptibility to re-infection (Hagen et al., 1991), although there is some evidence that praziquantel may actually trigger a degree of immunity (Vereecken et al., 2007). Dunne et al. (1992), Satti et al. (1996) and Karanja et al. (2002) have suggested that immunity to infection from $S$. mansoni can develop in some groups as a result of high antibody levels immediately following treatment (i.e. IgE antibodies), but immune responses of this kind do not seem to occur in children (Walter et al., 2006). Also, as Pinot de Moira et al. (2010) have suggested, it is possible that age-related differences in re-infection might be linked to the balance between different antibodies (IgE and IgG4), and that other observed rates of reinfection can be attributed to variations in exposure.

Whatever the impact of praziquantel on human immune responses, there is no doubt that, without changes in livelihoods, the risk of re-infection with schistosomiasis can be expected to be very high for most people living in endemic regions. Even if there is some (probably short-term) immunity triggered in adults, without periodic re-treatment, the prevalence of infection is likely to return to baseline levels. This is reported to have been 
the case, for example, in parts of Mali (Clements et al., 2009), north-western Uganda (Parker \& Allen, 2011) and Gezira Province, Sudan. The data from Sudan are especially troubling because it was anticipated that the approach adopted by the Blue Nile Health Project from 1979 to 1990 would become a model for others to follow elsewhere. The Project combined mollusciciding with the annual mass treatment of children with praziquantel. In other words, it was more than a vertical deworming programme. However, Mohamad's longitudinal study (Mohamad, 1993) of 4200 children (ranging in age from 7 to 16 years) found that the prevalence of $S$. mansoni had not fallen as much as expected. It had declined from a baseline level of $72.7 \%$ (recorded at the end of the 1980 s) to $54.7 \%$ in 1992. Since then, the prevalence of infection has returned to levels that are as high as they were before the Blue Nile Health Project began - i.e. above $70 \%$ (Amin, personal communication, 2013, and Amin \& El Hussin, 2009).

In terms of the safety of combining the deworming drugs, the WHO has taken a lead in claiming that individual diagnosis of infection is not necessary and that it is safe to give tablets to uninfected children (WHO, 2001, 2003, 2005a, b). However, Gryseels (2006) was correct in that rigorous, or even basic, monitoring of what happens when these drug combinations are given to impoverished people (who may be malnourished and heavily infected with multiple diseases) has generally not occurred. Research carried out in Uganda and Tanzania has shown that deworming tablets can have side-effects, which are viewed as serious in local terms. Many children complained of stomach upsets after being treated in schools, some adults were incapacitated for days, and there were uncorroborated rumours that a few individuals had died (Parker et al., 2008). Such experiences and stories led to widespread anxiety and fear, and fostered rumours about the real purpose of the treatments. They also prompted a different kind of resistance in the form of a refusal to distribute or take the tablets, and occasionally confrontations with angry parents (Parker \& Allen, 2011; Hastings, 2016).

Such reactions of irate parents relate to the underlying ethics of the deworming enterprise (Parker \& Allen, 2013b). Treatment has no demonstrable positive effect on non-infected individuals. If schools in a high-income setting were instructed to treat all children with a drug regime that would only benefit a minority, it would raise concerns. Indeed, it would probably be viewed as completely unacceptable to roll out such treatment without securing the consent of parents beforehand. Perhaps sufficient communication and discussion occurs in some locations in Africa, but research findings from Uganda and Tanzania, as discussed further below, show that in most cases tablets are given out in schools and to the neighbouring populations with no proper consultation (Parker et al., 2008; Parker \& Allen, 2011; Parker \& Allen, 2013a, b). Teachers themselves almost invariably stated that they did not really know why the tablets needed to be taken on an annual basis, and very few could accurately explain the aetiology of the diseases.

Moreover, the poor quality of health education materials (including pamphlets, booklets and posters) accompanying drug distributions reveals how little thought has been given to conveying information in an appropriate and effective way. To give just one example, children infected with urinary schistosomiasis (S. haematobium) are likely to present with blood in their urine until their teenage years, whereas children infected with $S$. mansoni are unlikely to notice any symptom at all. East African primary school text books, pamphlets and posters mostly describe $S$. haematobium, and focus on the red 
urine as a sign of infection (this includes the widely circulated cartoon story booklet described by Stothard et al. (2016)). Health education thereby gives the misleading impression that schistosomiasis is an affliction of childhood, and also that children without bloody urine are unaffected by the disease. It is a cause of considerable confusion in places where $S$. mansoni is endemic (Parker et al., 2012).

\section{Evidence from deworming trials}

The points above all relate to Gryseels' remark that mass deworming is based on poor science and poor public health practice. A further set of issues relate specifically to the way in which the effectiveness of medical programmes is usually assessed by epidemiologists. Work by epidemiologists focusing on deworming includes cohort studies, such as those of Kabatereine and his colleagues in Uganda, and randomized control trials (RCTs). The latter are often held up as the 'gold standard' in evaluating evidence within global health, and by many micro-economists who seek to replicate the approach in various kinds of social experiments. For some scholars, all other approaches are anecdotal or unscientific. However, in practice, RCT trials differ in quality (Grossman \& Mackenzie, 2005). Results are affected by their design and implementation, and if used exclusively as the source of evidence, useful information from observational and inductive research may be ignored. Moreover, even among those accepting the hegemony of the RCT approach, there are divergent opinions about the appropriate specificities of RCT-type studies. The Cochrane Review process, which collates findings from multiple RCTs, includes studies described as 'quasi-RCTs', suggesting a degree of subjective consideration about what is deemed suitable for inclusion in a systematic review. In addition, economists and epidemiologists can have widely contrasting views about the reliability of results, particularly when the data are messy. As a discussion published in the Economist observed, this explains at least some of the divergence in views about Miguel and Kremer's 2004 paper (Economist, 2015).

In the particular context of deworming, there is a further problem. A 'proper' RCT may be considered unacceptable, if those running the study are already convinced that a particular treatment is effective. It is only ethical to have a control group if a drug or medical procedure is not known to be better than an alternative treatment or no treatment. For those already convinced about the safety and efficacy of the tablets, it is unethical to subject people to experimentation, and inappropriate to spend limited resources proving an impact that already has a sufficient evidence base. This is one reason why the kind of 'large scale, randomized, multi-country, long-term evidence' that Blattman suggests would be appropriate for deworming has not been produced (Blattman, 2015). It is also why some studies that have attempted to do something approximate to an RCT in the context of deworming can be viewed as flawed when set against the most rigorous criteria.

An effort has been made to collate studies of deworming that are close to the ideal RCT format in an on-going review by the Cochrane Library group, continuing the work of Dickson et al. (2000), mentioned above. In 2012, the team published an integrated overview of the results of 42 trials of deworming, some dating back to the 1970 s, but most since the 1990s (Taylor-Robinson et al., 2012). Their review included 20 RCTs 
undertaken in Africa, with half of them taking place in East Africa (including Miguel and Kremer's 2004 study in Kenya). It was concluded that it is 'probably misleading to justify deworming on the basis of school performance or attendance', and that evidence of deworming having impacts on nutrition, haemoglobin and cognitive function have not been clearly demonstrated. In a subsequent commentary paper, they related their assessment to the re-analysis of Kremer and Miguel's 2004 article, arguing that continued unquestioned commitment to deworming as a panacea that will solve multiple problems is perplexing, and that the belief that it will impact substantially on economic development seems 'delusional' (Garner et al., 2015). Then, in the 2015 update of the review, the results from three more trials were added, including one with a million participants in India. The team now concludes that there is 'quite substantial evidence that deworming programmes do not show benefit in terms of average nutritional status, haemoglobin, cognition, school performance, or death' (Taylor-Robinson et al., 2015).

Kremer and Miguel have reacted to the Cochrane Review findings by arguing that their 2004 article is not the only study documenting the educational and economic impact of deworming, and that these were misleadingly excluded (Kremer \& Miguel, 2015). Such studies include follow-on research from their 2004 paper. This is based on longitudinal observations of groups of Kenyans from Busia who were dewormed as children. It was not assessed by Taylor-Robinson et al., presumably because it has not yet been published in a final form, has not been independently reviewed and is not a randomized trial. A cohort who are likely to have received treatment for intestinal helminths in 1998 and 1999, as well as health education, have been tracked and compared with a group who are less likely to have received treatment in 2001 (because of an attempt to introduce a charge for treatment in that year, prompting very low take-up of the tablets). The work has been heavily promoted at the World Bank by Bundy, as mentioned in the introduction of this article. It has been circulating in various forms as a working paper called 'Worms at Work' since 2010 and has recently been updated (Baird et al., 2015). Remarkably, this latest version continues to repeat the miscalculated headline figure from Miguel and Kremer's 2004 paper that deworming treatment reduced school absenteeism by one-quarter (Baird et al., 2015, p. 3).

According to Kremer and Miguel, the 'Worms at Work' research shows that: ' 10 years after deworming, Kenyan women who were dewormed for more years as girls were $25 \%$ more likely to have attended secondary school, and men who were dewormed for more years as boys worked $17 \%$ more hours and had better labour market outcomes, including higher earnings' (Kremer \& Miguel, 2015). It is hard to interpret these results. The suggested long-term effects of not deworming children in one particular year (i.e. 2001) need to be assessed in relation to specific information about the helminth infections in question, as well as the actual consumption of particular drugs over time. Among other things, it would be important to know why children who were treated in other years were not re-infected, and why those children who did not receive any treatment in 2001 were not treated in any other years. There is an undiscussed suggestion that free deworming introduced in all study schools from 2002 failed, or at least failed to reach anyone not treated in 2001 (Baird et al., 2015, p. 7). In sum, the 'Worms at Work' study in its current form raises many more questions than it answers. Nevertheless, Kremer and Miguel argue that it challenges the Cochrane Review's findings, and 
they claim that: 'Multiple organizations have carefully reviewed all the evidence on deworming, and concluded that mass drug administration is highly cost-effective' (Kremer \& Miguel, 2015).

One such organization is GiveWell. In 2015, following an ostensibly impartial assessment, it has continued to rank two leading deworming initiatives in its list of four 'top charities' (GiveWell, 2015). GiveWell accepts the Cochrane Review's findings that there is little sign of short-term impacts of deworming on health indicators or test scores, but it believes that this does not undermine the plausibility of the effect on earnings. In a discussion of the re-analysis of Miguel and Kremer's 2004 paper, GiveWell basically agrees with Miguel and Kremer's response, and also follows their example by giving particular emphasis to their on-going cohort study. Citing data from a table in the 2012 version of the 'Worms at Work' working paper, GiveWell claims the implication is that 'deworming is $~ 50$ times more effective than cash transfers'. It accepts that this astonishing calculation may be inaccurate, yet goes on to argue that there is a good case for donating to support deworming, 'even when in substantial doubt about the evidence' (GiveWell, 2015). Others have gone a stage further in completely rejecting the Cochrane Review process.

De Silva et al. (2015) have claimed that 'the Cochrane Systematic Review methodology is not appropriate for assessing the impact of mass deworming programmes in endemic communities in developing countries' and Montresor et al. (2015) have argued that it is of little value in guiding global deworming policy. The main reasons given for setting aside the collated findings of randomized controlled trials is that evaluations need to occur over longer time periods to discern the benefits, and also that the trials have included in their assessments those children who were not infected, thereby diluting the overall positive effects. The latter is, of course, an inevitable consequence of the mass treatment approach, because there is no individual diagnosis of children before treatment. It suggests that a randomized controlled trial can never be an inappropriate method for evaluating the intervention. Instead, it is suggested, that a 'proper evaluation should be organized' (Montresor et al., 2015, p. e0004165). It is not explained what a 'proper evaluation' would involve, but for a WHO official like Montresor to call for one would appear to be a surprising admission that no such evaluation has ever actually occurred. Perhaps most remarkably of all, the WHO's Advisory Group on Neglected Tropical Diseases has responded to the Cochrane Review by setting it aside. It has simply re-asserted that research shows deworming children is an effective strategy, and it has endorsed the WHO's recommendation for mass treatment (WHO, 2015). Negative reactions to the Cochrane Review were predictable, given how much is at stake, but for the WHO to set aside the collated results of relevant randomized controlled trials in this way is surely unprecedented.

Meanwhile, there are a couple of issues that have been lost in the exchanges. First, as Taylor-Robinson et al. note in passing, Miguel and Kremer's research is one of the only trials included in the Cochrane Review to assess deworming with a combination of albendazole and praziquantel. They write about 'intestinal helminths', with S. mansoni included in that category; and they do not disentangle the effects of treating such a wide spectrum of diseases in the same programme. It is thus possible that their results are affected by a reduction in the prevalence and/or intensity of schistosomal infection, rather than a reduction in the prevalence and/or intensity of infection of various 
soil-transmitted helminths (or vice versa). This is also a confounding factor in their subsequent 'Worms at Work' cohort study. Of the helminth infections mentioned in Miguel and Kremer's 2004 paper, S. mansoni is the only one that might have the longterm effects indicated in Baird et al. (2015). If the 2001 cohort was heavily infected and never treated, after years of being asymptomatic, as young adults, they could have less energy than the cohort given praziquantel in the late 1990s. It is worth noting in this context that Parker's long-term research on S. mansoni in Sudan during the 1980s demonstrated that infection levels had no effects on infant and child growth, and that both the children and adult women she lived with had no subjective awareness of their infective status (Parker, 1989). Moreover, women with very high infection loads were still able to gather as much cotton from the fields as women who were uninfected. However, they needed more rest, and therefore had to work faster (Parker, 1992, 1993).

Second, although both Kremer and Miguel have been active in promoting deworming, and have not objected to the way their data have been used, the findings of their 2004 article do not really contradict the overall conclusions of Taylor-Robinson and colleagues. In 2004, they explicitly stated that although they felt there was strong evidence for an improvement in school attendance, they themselves did not find evidence that deworming improved academic achievement (as measured through examination performance). In other words, back in 2004, Miguel and Kremer were more moderate in their claims about deworming on schooling than has sometimes been suggested. In addition, they foregrounded potential problems arising from school-based deworming in the discussion of their results. Drawing on insights from anthropologists and other social scientists, as well as biomedical researchers, they emphasized the importance of social learning and other behavioural factors influencing the uptake of medications.

They elaborated these points in an important article published in 2007, emphasizing the hazards of generalizing findings from one social group to another (Kremer \& Miguel, 2007). They found that families outside of the trial group, but friendly with families in the trial group, were less likely to deworm their children than families who were not friendly with those who had been part of the initial control group. Thus, contrary to external expectations, adults did not necessarily perceive treatment as beneficial for their children's health and well-being, and they were not necessarily willing to let their children participate in school-based treatment programmes. They also found that a school-based health education intervention had no discernible impact on worm prevention behaviours and that requesting a small payment for drugs (in 2001) led to an $80 \%$ reduction in treatment rates. This, in turn, suggested that school-based treatment had not created a demand for treatment. The purported benefits of deworming were not locally appreciated, and commitment to de-worming in the population was low. They concluded that reading too much into their earlier results gave an 'illusion of sustainability'.

Such an illusion of sustainability has been shown to be a problem with other deworming studies too. It particularly applies to research, based on small samples or longitudinal cohort studies in places where school-based treatment has been attempted on a large scale. This is notably the case with respect to Uganda, which introduced the first integrated national mass drug administration programme for the control of schistosomiasis and soil-transmitted helminths at around the time that Miguel and Kremer's 2004 paper was published. Deworming in schools as well as communities was a 
major component of the programme; and tremendous achievements were quickly asserted (Kabatereine et al., 2007; Zhang et al., 2007). However, the degree to which the results from these cohort studies are useful in assessing the effectiveness of deworming is open to question (Parker \& Allen, 2011).

For example, the article cited above by Kabatereine et al. (2007) was based on a study of school children who were monitored 6 months after each annual treatment. If a child was infected with S. mansoni or soil-transmitted helminths, on ethical grounds, they received an additional treatment (personal communication with the lead author). Thus, the cohort study documented changing patterns of infection following treatment at 6-monthly intervals; and this placed the cohort apart from other children in the same schools who were only offered treatment once every 12 months (and who were not part of the study).

In addition, the cohort was biased towards children from families who were sufficiently wealthy to stay in one place and cover the costs of their children going to school for the duration of the study. With large numbers of children in under-resourced and rural parts of Uganda failing to complete their primary education, it proved problematic to extrapolate the findings to the wider school-aged population. Indeed, the study had to be stopped after 3 years, because so many children had dropped out of school (Parker \& Allen, 2011). This last point would seem to counter Miguel and Kremer's finding in Kenya that deworming was linked to improved school attendance, but it may be largely explained by another factor. Many of the families of the children surveyed were involved in fishing and fish-processing. As a result, children often moved from one location to another. In some cases, they spent time in remote fishing camps or across the border in the Democratic Republic of Congo (Parker et al., 2012). A cohort study which relies on the continuous and stable residence of those participating is thus likely to end up reporting findings for non-fishing families and that is a problem when it comes to schistosomiasis.

\section{Doing deworming in East Africa}

Points have been raised in the sections above about the robustness of data analysis based on particular study sites and sample groups. However, there has been much less focus on the degree to which such research represents what happens in schools and wider populations that are not closely observed in surveys. As Kremer and Miguel suggested in their 2007 paper on the 'illusion of sustainability', it should not be assumed that they do, while in a paper they published in 2002 they discussed specifically why so many people in Kenya choose not to take deworming medicines (Miguel \& Kremer, 2002; Kremer \& Miguel, 2007). Deworming can only be effective as a public health strategy if the tablets are consumed. So, what is the evidence that those offered free deworming tablets actually swallow them?

The expectation is that children will generally do so if they are appropriately instructed by their teachers, even if there is not a demand for treatment among adults living nearby. However, a difficulty with finding out if they do in fact receive the tablets is that systematic monitoring of both school and 'community' distributions is haphazard. Resources for rolling out large-scale preventive chemotherapy are generally concentrated at higher levels in the supply chain. In East Africa, school distributions are provided by teachers who receive minimal training, while distributions in villages 
rely less on qualified health workers and more on volunteers (otherwise known as 'community drug distributors'). A range of problems have been reported, including the fact that poorly trained teachers and volunteers are rarely able to provide convincing explanations of the need to take medications, especially when someone has no signs or symptoms of infection (Parker \& Allen, 2011; Samsky, 2012). The message to consume tablets also runs counter to other concurrent health education messages, such as those about the use of anti-malarials, which emphasize the need for individual diagnosis before consuming medicines.

In addition, the emphasis on community volunteering is largely premised on a false conception of how people in African countries live their lives. For example, it is frequently imagined that people live in bounded, geographical areas and that social relations are harmonious within this space. As a result, it is assumed that villagers will be willing to distribute medicines, without remuneration, in the interests of promoting the health of 'their community'. The reality is often quite different. In Panyimur Sub-county of Nebbi District, north-western Uganda, for example, villages can be widespread, with homes in lakeland and highland locations. It is unrealistic to expect drug distributors to spend days walking long distances in search of people who they may barely know, and perhaps do not really like. There is, too, an unwillingness and/or inability for those running the mass distributions to train health workers and volunteers sufficiently well, such that they feel able to engage with anxieties and concerns being articulated about the treatments at a local level. For rural primary school teachers this may also be an issue, particularly if they do not live in the immediate vicinity. As one World Bank study observed, the problems with deworming in schools not only include absenteeism among children, but also absenteeism among teachers. At the Ugandan primary schools surveyed, 27\% of teachers were found to be absent when they were ordinarily scheduled to teach (Halsey Rogers, 2005). If teachers are not present to distribute tablets, there may be no distribution at all, or the under-staffing may be such that it cannot be carefully managed and recorded.

A further issue, and one that is often ignored, is that the tablets themselves are very different from each other. Albendazole has a sweet taste, and those heavily infected with soil-transmitted helminths may observe worms coming out of their bodies in faeces. Moreover, it is common in East Africa for livestock and domestic animals (notably dogs) infected with helminths to be treated with albendazole tablets (which can usually be bought in local shops). Again worms may be observed being expelled. Treatment with praziquantel is very different. Several tablets have to be taken at once, and they are both large and pungent. Swallowing them can present a challenge, even for those wanting to do so. Also, those being given treatment may have no discernible signs or symptoms of schistosomal infection, but may experience side-effects. Vomiting, diarrhoea and fainting can occur. Comparable problems arise with the treatment for lymphatic filariasis. Ivermectin is easier to swallow than praziquantel, but again the tablets need to be taken before there are any visible indications of infection. The fact that local understandings of the disease rarely coincide with those of biomedicine, and taking the tablets has no observable effect on lymphoedema, compounds the problem (Parker \& Allen, 2013a).

Against this background, it is hardly surprising that teachers and community distributors do not necessarily implement deworming as planned. Recent data on disease prevalence, where they are available, suggest that either they do not do so, or that the children are quickly re-infected. For example, despite the huge numbers of Kenyan 
children reportedly treated (KNSDP, 2014), rates of infection remain relatively high. A recent study of $S$. mansoni and soil-transmitted helminths has been carried out in the west of the country, not far from where Miguel and Kremer have been researching in Busia since the $1990 \mathrm{~s}$. It found that $65.6 \%$ of children were infected with one or more intestinal helminth species (Odiere, 2012). Other recent research, specifically on soil-transmitted helminths, studied 153 schools in Busia and neighbouring counties (Nikolay et al., 2015). Following several years of free mass drug administration, the combined prevalence for soil-transmitted helminths among school children was $34.8 \%$ in 2012. After two further rounds of closely monitored treatment, overall prevalence fell to $19.7 \%$ in 2014 . At many schools, no significant change in the prevalence or intensity of infection was recorded. Where there were more positive outcomes, they were associated with better sanitation, better health services and better economic indicator scores. In other words, deworming alone was largely ineffective.

Since 2005, research undertaken by the authors and their students has found comparable problems in other parts of East Africa (Aldis, 2008; Wingate-Saul \& Shira, 2008; Parker et al., 2008, 2012; Parker \& Allen, 2011, 2013a; Ozunga, 2014; Pearson, 2016; Hastings, 2016). Field sites were located in north-western Uganda (Nebbi, Buliisa, Adjumani and Moyo Districts), south-eastern Uganda (Busia District - just across the border from where Miguel and Kremer studied deworming in Kenya), Tanzania's Ukerewe Island in Lake Victoria, Tanga Region in northern coastal Tanzania, and Morogoro Region, which lies to the west of Dar es Salaam (see Fig. 1).

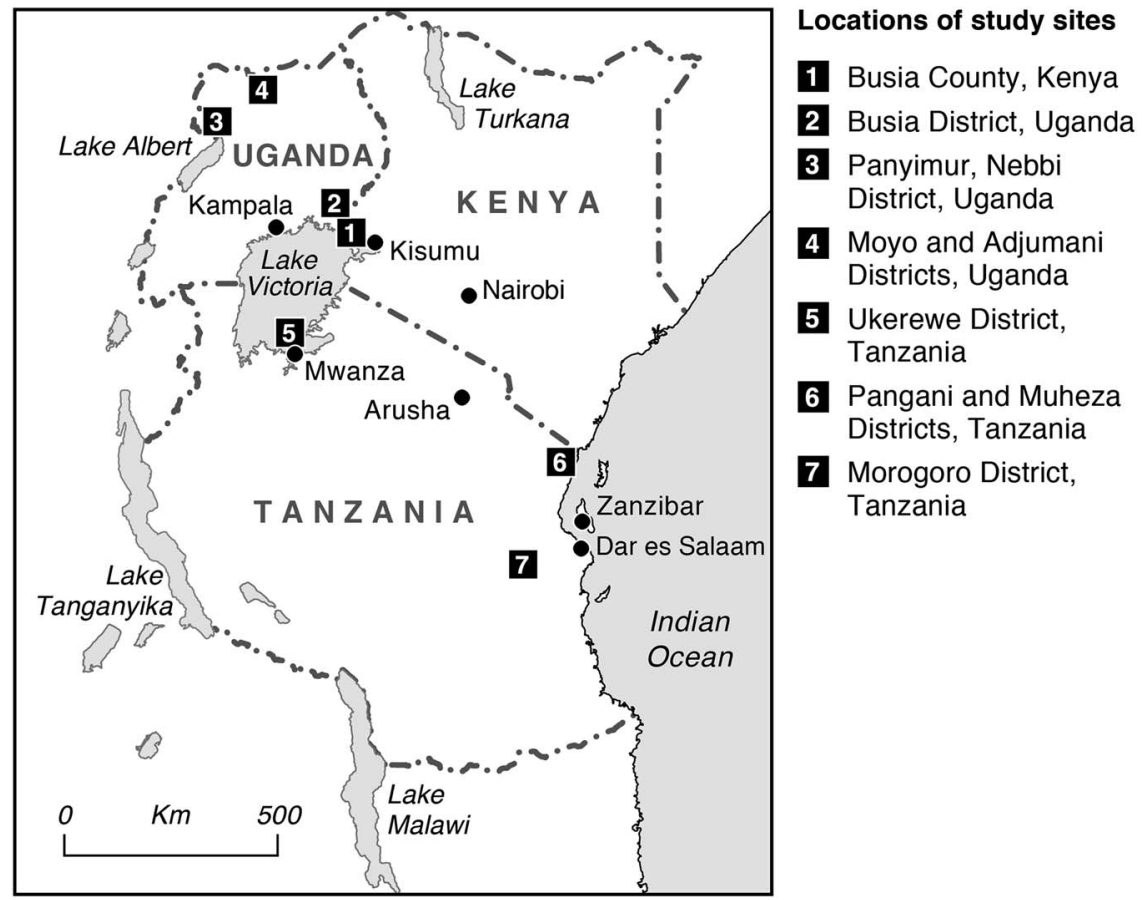

Fig. 1. Map of East Africa showing study sites. 
Research methods involved the following: observing mass drug administration in villages and schools; documenting drug coverage levels among 10-20\% randomly selected households and, where possible, comparing these data with drug coverage levels recorded in Ministry of Health registers; focus group discussions; and open-ended, unstructured interviews with a diverse array of people including school teachers, political and religious leaders, health workers, village drug distributors and adults, including the parents of children receiving preventive chemotherapy. The research was mainly focused on 'community' responses, and separate self-reported surveys of drug take-up by children were not carried out. However, research occurred in schools at all sites and efforts were made to assess drug coverage levels from the registers. In most cases, there were no reliable registers of those children who were observed by teachers as having swallowed the tablets. Instead, where possible, the school registers of children attending schools at the start of the academic year were compared with those attending schools on the day(s) the school teachers were distributing drugs. Discussions and other exercises (such as drawing pictures and writing essays relating to deworming) were also run with pupils (usually in classroom settings). Finally, efforts were made to observe school distributions, and to locate and interview the families of children who were absent when drugs were being distributed, or who refused to take the tablets.

\section{Is deworming effectively delivered in Ugandan schools?}

Investigating drug uptake in Ugandan schools was challenging. It was not possible to collect identical information from all research sites, because class registration and attendance registers were often missing, and the haphazard and unpredictable nature of drug distribution made it hard to plan observations in advance. Distributions would often be cancelled and then might occur suddenly and quickly, without prior warning. Occasionally, too, the teachers would receive the tablets, but they would not distribute them if they thought the distribution was going to be monitored (presumably because they did not want to be held to account if the distribution did not occur correctly). Nevertheless, it was possible to estimate drug uptake at many schools in Uganda. Overall, the uptake of praziquantel by children in schools was higher than the rate reported by Muhumuza et al. (2013) from Jinja, although it was very variable, and still well below the WHO's 75\% target. Examples are provided below.

In Busia District, the prevalence of helminth infections in children was said to have been very high in the past. A baseline study was carried out in the neighbouring area of Kenya, called Busia County, in 1989, by a team that included Miguel, Kremer and Bundy in anticipation of the school-based deworming programme that Miguel and Kremer analysed in their 2004 article (Brooker et al., 2000). A total of 1738 pupils aged 8-20 years were randomly selected from 25 schools to participate in the study. Overall, $91.6 \%$ of the pupils were infected with $A$. lumbricoides, T. trichiura, hookworm or S. mansoni. Co-infection was common. Hookworm was the most prevalent helminth, but infection with $S$. mansoni was above $50 \%$ in three schools close to Lake Victoria, and above $30 \%$ in three other schools (Brooker et al., 2000). More recently, a survey of school-aged children living in lakeside and island locations in the Ugandan district next to Busia found that $75 \%$ of children were infected with $S$. mansoni and $33.6 \%$ were co-infected with soil-transmitted helminths (Kabatereine et al., 2011). 
In Busia Districts's Lumino Sub-county, extensive efforts were made to assess schoolbased treatment, but the drug distribution registers were either missing or incomplete. Those available were simply a list of children who had ostensibly been given the tablets, with no indication of how many had not received them. Attendance data from class registers of eight selected schools were thus manually counted and, wherever possible, compared with school attendance records on the day of distribution and to school enrolment figures. It was established that a total of 6518 children were registered at the study schools, of which 2567 were offered school-based treatment in 2009. Possibly, the enrolment numbers had been inflated, because schools secure funding on the basis of student numbers. Taking this into account, it can be estimated that about half of the children targeted for deworming actually received the tablets. A small amount of treatment may have been provided to children in 'community' distributions, but it was not extensive. The volunteers had been instructed not to provide tablets for them, because treatment was supposed to occur in schools. Data were additionally found at six of the schools for 2008. According to these data, 5359 children were registered at the start of the academic year and $3438(64 \%)$ of these children were recorded to have been present on deworming days. It was hard to find good explanations for why reported rates were higher in 2008 than they were in 2009. As elsewhere, the experience of side-effects in the earlier round of treatment was one factor mentioned.

In locations researched around the northern shore of Lake Albert, rates of infection with both schistosomiasis and soil-transmitted helminths are similarly known to have been very high in the past. Studies carried out in the early 1970s indicated that the overall prevalence of $S$. mansoni was around 90\% (WHO, 1987). Prevalence was also assessed in the mid-1990s before widespread deworming. It was found to be between $80 \%$ and $90 \%$, with infection peaking in the 10-14 years age group (Kabatereine et al., 1992, 1996). Yet, despite these high infection levels, active hostility to mass drug administration was observed in 2005. In Panyimur Sub-county, located close to the border with the Democratic Republic of Congo, many adults were willing to take albendazole, but they refused to swallow praziquantel and they clearly did not want it to be given to their children (Parker et al., 2008, 2012).

In this context, teachers were understandably nervous about distributing the drugs. Some children ran away to avoid treatment. The examination of school registers revealed a further issue: only a small proportion of children complete primary school education. At schools for which there were well-kept registers, it was found that only a quarter of children registered in 'P1' (i.e. the first school year) were likely to still be attending school 7 years later. Girls were especially likely to drop out. In 2008, for example, registers were examined at nine schools. A total of 908 boys and 835 girls were registered in year one, but these numbers had dropped by almost $50 \%$ by year five, and only 121 boys and 48 girls were attending the schools in year seven (Aldis, 2008).

In 2014, it was found that record keeping on drug distributions had improved, and it was possible to compare the number of children enrolled in a class at the start of the year, and those registered as present on the days of tablet distribution. Combining data from three schools, a total of 2813 school children were enrolled and $1388(49 \%)$ of these children attended school on the day that deworming occurred. Teachers claimed that all those children present swallowed the tablets. However, drug coverage varied considerably between the schools, with teachers recording coverage rates of $65 \%, 46 \%$ and 26\% respectively (Ozunga, 2014). 
Given the initial high infection rate, the antipathy to deworming in the area in 2005, and problems with the school distributions, it is hardly surprising that the programme has had limited impact. After several annual rounds of school-based and 'community' deworming, prevalence remained very high. In 2008, for example, a study was carried out under the auspices of the Ministry of Health in two primary schools in the sub-county. At each school, 60 children were tested for $S$. mansoni in four age groups: 6, 7,8 and 11 years. At one school, the percentages of children positive in each group were $91.7 \%, 91.7 \%, 76.7 \%$ and $98.3 \%$ respectively. At the other school, located closer to Panyimur town centre, rates were a little lower, but rose to a similar level by age 11 . The rates recorded in each group at that school were $60 \%, 65 \%, 81.7 \%$ and $96.7 \%$ respectively (Aldis, 2008; Parker et al., 2012).

Following the River Nile out of Lake Albert towards the South Sudan border, there are considerable local variations in the prevalence of infection with S. mansoni. In locations around Rhino Camp and Obongi, a prevalence of more than $80 \%$ was recorded in the early 1990s (Odongo-Aginya et al., 2002), but a few miles to the north, a rate of close to $30 \%$ had been reported for the area between Laropi and Dufile, Moyo District, in 1987 (Nelson, reported in WHO, 1987). More recent data are confusing. The Ugandan Ministry of Health assessed the prevalence of $S$. mansoni among children sampled at two schools in Dufile and Laropi trading centres in 2003, and found rates as low as $5.3 \%$ and $1.6 \%$. Yet, the prevalence was reportedly $40.4 \%$ among adults in Laropi in the same year. These data were collected prior to the mass distribution of drugs. Matters are further complicated by the fact that the prevalence reportedly rose to $9.6 \%$ among children in Laropi one year after treatment but fell to $5.6 \%$ among adults (Parker et al., 2012).

In this area around Laropi, deworming has only occurred at schools located close to the Nile. In July-August 2008, research took place at five selected primary schools receiving tablets in Adjumani District, on the opposite bank of the river, over a period of 6 weeks. All these schools had accurate class registers. A total of 2179 children were registered at the start of the academic year in 2008, with 1078 (49.47\%) being recorded as having received praziquantel. The proportion of children receiving treatment varied considerably between schools, with the lowest uptake being $27 \%$ and the highest uptake being 65\%. Unlike Panyimur, there was little difference between boys and girls in terms of uptake. Differences in drug coverage between the schools were linked by teachers to the availability of food at the time of distribution. Some schools received food relief from international aid agencies, because they were accommodating refugees from nearby war-affected locations in South Sudan. When tablets were distributed with food, uptake was noticeably higher.

Mass drug administration also occurred in the wider riverine population, with much less dissent than was noted in Panyimur, but with logistical difficulties in reaching fishing families who were working and often living on small islands or at remote landing sites. However, in 2013, one of our research team documented the prevalence of S. mansoni among these fishing families, and found it to be below $4 \%$. The prevalence of soil-transmitted helminths was also low - ranging from $0 \%$ at the majority of sites to $11 \%$ at the worst affected location (Pearson, 2016). Thus, despite the variable coverage levels in schools and in the general population, the prevalence of infection with intestinal helminths is at a lower level than might be expected. This is in marked contrast to sites 
close to Lake Albert in Panyimur Sub-county, where ways of life are similar. It is far from clear how to explain these differences. Deworming may well have played a part, but it is impossible to know by how much from the available evidence.

In Moyo and Adjumani, as in other study sites in Uganda, albendazole was supposed to be provided to the children in schools alongside praziquantel. At all sites, the records were not adequate to analyse the differential take-up of these two drugs, so it is not possible to say that more children were, in practice, willing to take albendazole than praziquantel. Nevertheless, fears about consuming the tablets were almost invariably related to praziquantel rather than albendazole. The latter was widely available at dispensaries and local shops, and was used for the treatment of intestinal worms when visible symptoms presented in both humans and domestic animals.

Recently, consumption of praziquantel by children in Uganda has also been studied by another research team in the area around Jinja (Muhumuza et al., 2013). The findings have tended to confirm those presented above. The prevalence of schistosomiasis was found to be $35 \%$ at the time of fieldwork in 2011. A random sample of 1010 children in twelve primary schools were interviewed. Self-reported uptake of praziquantel was found to be $28.2 \%$. Of the 285 children who took praziquantel, 142 developed side-effects. Of those that did not take the tablets, $72 \%$ reported a fear of side-effects as a major reason. In a later article, the same authors explored why take-up was so low (Muhumuza et al., 2015). In addition to concerns about side-effects, the reasons cited included inadequate information about the prevention of schistosomiasis, poor training of teachers and problems with the school feeding policy (which was meant to ensure the tablets are not taken on an empty stomach).

\section{Is deworming effectively delivered in Tanzanian schools?}

In Tanzania, drug distribution in 'communities' was found to have faced similar difficulties to those in Uganda, but school-based treatments were generally more successful - with notable exceptions in Morogoro in 2008. School distributions on Ukerewe Island were particularly impressive. The island has long been a place of study for the National Institute for Medical Research (Mwanza), and awareness of schistosomiasis as an illness affecting children is widespread. However, continuous reinfection remains a problem. A study carried out at the end of the 1990s estimated that the prevalence of S. mansoni was above 90\% (Mwanga, 2005). More recently, research on Ukara Island, which is part of Ukerewe District, found that $63.91 \%$ of a sample of 609 children aged 4-15 were infected with $S$. mansoni and $6.73 \%$ were infected with soil-transmitted helminths (Mugono et al., 2014).

Research on Ukerewe Island took place at seventeen schools, over a period of 6 months in 2007 (Wingate-Saul \& Shira, 2008). During this time, it was possible to observe school-based treatment and compare the number of children registered at sixteen primary schools with the number of children reported to have consumed the drug, praziquantel, in the drug registers kept by teachers. There was only one school where the registers documenting drug uptake among school children could not be located. These data were subsequently compared with information collected on selfreported drug uptake among adults. Only praziquantel was distributed, because of a delay in the arrival of albendazole tablets. 
According to the registers kept by school teachers, the uptake of drugs in 2007 ranged from $60 \%$ to $87 \%$, with the average coverage level being $72.4 \%$ - close to the WHO target of $75 \%$. It is interesting to note, however, that the reported rate of take-up by children in the schools that was submitted to district headquarters were substantially higher in half of the schools studied. A school that achieved a $61 \%$ take-up reported that take-up was $96 \%$, and another that achieved $60 \%$ reported that take-up was $80 \%$. Even staff at a school that achieved $82 \%$ felt the need to exaggerate, reporting take-up of $97 \%$. This tendency to overstate take-up rates was something observed at all field sites in Tanzania, often making official estimates of coverage misleading. It was probably a problem in Uganda too, but in Tanzania, the local-level registers were sometimes found to be well kept and accurate, so it was possible to check. Findings from Ukerewe Island also reflect another characteristic of deworming programmes at all the Tanzanian study sites in that relatively high take-up in schools is not matched in nearby 'communities'. Adult take-up in Ukerewe Island was assessed by a survey of $20 \%$ of households in fourteen villages. The average adult self-reported take-up of praziquantel at these locations was $44 \%$, and ranged from $18 \%$ to $74 \%$.

Across the other side of Tanzania, in coastal Tanga Region, it is S. haematobium that is endemic rather than $S$. mansoni. An assessment made in the late 1990s estimated that in $26.1 \%$ of 591 schools surveyed, the prevalence was $50 \%$ or above (Brooker et al., 2001). A baseline study of 466 children aged 8-14 years in the region suggested that $59 \%$ of children were infected with $S$. haematobium. Soil-transmitted helminths were also found to be common, with $61 \%$ of children infected with hookworm, and $37 \%$ of children infected with both hookworm and S. haematobium (Guyatt et al., 2001). These findings were used to argue that school-based deworming with praziquantel and albendazole should be prioritized. However, lymphatic filariasis is also endemic in the region. In one location, $63 \%$ of those tested in 2004, aged 10 and above, were infected, and $33.6 \%$ had indications of chronic disease (Simonsen et al., 2013). It was therefore decided to treat all people over the age of five in such places with a combination of ivermectin and albendazole. This meant that only praziquantel was used in school-based deworming. An unforeseen consequence was that the uptake of tablets by children living in the area was high for $S$. haematobium (in so far as it could be assessed), but was low for soil-transmitted helminths and lymphatic filariasis. That was because the community distributions of ivermectin and albendazole were unable to achieve anticipated levels of coverage. In most of the villages studied, less than $40 \%$ of the population reported that they had taken the tablets (Parker \& Allen, 2013a).

It was not possible to locate accurate records for the praziquantel distributions in the majority of schools visited, but at those for which data were available, the target of $75 \%$ coverage was exceeded. In one school in Pangani District, for example, 229 pupils were registered in 2007, and 184 of these children were reported to have received praziquantel. A further five children, who were not enrolled in the school, were also treated. Meanwhile, in the same year, 70 of the 71 children registered at Mrozo, a small school in Muheza District, were reportedly treated, and a further five who were not enrolled were treated too. When Mrozo was visited in July 2007, however, students were asked to raise their hands if they had blood in their urine, and more than half of them did so. Either they had not in fact been treated, or they had been re-infected. Sufficient tablets for treating the whole school were found to be available in the storeroom, and a phone call 
to the district headquarters secured permission for the teachers to distribute them immediately, but they were unwilling to do so. They were worried the children would have side-effects if they had not first eaten.

Incidents like the one at Mrozo again suggest that officially reported take-up rates are over-estimates. Nevertheless, generally high coverage in Pangani and Muheza Districts was confirmed where it was possible to observe distributions. In 2007, distribution days were observed at ten schools in Pangani District. In all cases, teachers gave the impression of being committed distributors, even though the health education materials handed out and discussed with pupils on the day of praziquantel distribution were for soil-transmitted helminthiases rather than schistosomiasis. This latter point caused confusion among students who tried to compare the information in the leaflets with the information in their biology text-book. Nevertheless, the take-up of the drugs was for the most part orderly and disciplined. At three of the schools in which it was possible to check registers, the number of children absent was small. In all instances, it was fewer than ten. Head teachers interviewed were adamant that those children would be followed up and treated at home. No significant gender differentiation was noted in those receiving treatment.

At Morogoro, the third site in Tanzania, deworming in schools was particularly problematic. The difficulties that arose have been written up as part of a detailed study of mass drug administration in the region by Julie Hastings (Hastings, 2016). At many study sites away from Morogoro town, coverage in school distributions was found to be low, or to have simply not occurred. Then, in August 2008, the approach had to be abandoned, because rumours had spread about the distributed praziquantel tablets having adverse effects. Hastings herself had to be rescued by armed Tanzanian police from a school where a mob was threatening violence. Elsewhere, teachers were beaten up and school buildings destroyed.

\section{Conclusion: deworming delusions}

Many of the statements about public health benefits arising from indiscriminate deworming of East African school children are overblown. The findings of Miguel and Kremer's much referenced 2004 article on Kenya are flawed, and claims about declines in school absenteeism and positive externality effects are unconvincing. In addition, the collated results of randomized controlled trials from all parts of the world indicate that mass deworming in schools has no significant overall impact, suggesting that the co-option and redirection of national health programmes towards vertical drug distributions has been an error.

A response from those committed to mass drug administration has been to emphasize the purported long-term economic benefits of deworming, to seek some residual significance in Miguel and Kremer's data from almost 20 years ago, to raise doubts about the relevance of other randomized trials, and to highlight findings from selected cohort studies. It is certainly useful to draw attention to the need for different kinds of research, drawing on longitudinal and observational methods. However, positive findings on mass deworming from those approaches in East Africa are also open to question. Sample groups are not necessarily representative of wider populations, and it is very difficult to convincingly deal with confounding factors and to show causality. 
Miguel, Kremer and their colleagues are currently grappling with these issues in their on-going Kenyan work on employment trajectories (Baird et al., 2015), but it is not at all clear how they will manage to satisfactorily resolve them and far too much is being expected.

Currently, large-scale deworming programmes are underpinned less by evidence, than by a normative commitment, as well as the availability of medicines and funding. This does not mean that school-based treatment has no value. The point is that mass drug administration to populations with low levels of infection may not be a costeffective or appropriate way of reaching those children (or adults) in need of therapy, and it may not result in overall improvements in health outcomes over time. Where programmes can be shown to have positive effects, they are likely to be in places where there are high levels of infection, and declines in the prevalence and intensity of infection are probably connected with additional factors. With respect to soil-transmitted helminths, which are the focus of most school-based programmes, available evidence suggests that deworming only works well if there are improvements in sanitation, health services and other indicators of well-being.

It can also be misleading to generalize from claims about deworming for soil-transmitted helminths to deworming for other parasitic infections, such as schistosomiasis and lymphatic filariasis. The diseases have different aetiologies, and the medications work in different ways - with diverse biological and experiential effects. For example, research in East Africa has shown that praziquantel has side-effects, which may be perceived as serious by those being expected to swallow the tablets. Also, mass drug administration for $S$. mansoni and lymphatic filariasis requires medication to be taken on trust. Children usually appear to be healthy at the time they are asked to swallow the tablets, and they (and their parents) are less likely to understand the purpose of indiscriminate treatment (i.e. without diagnostic tests) than they are for those helminth infections with locally observed and understood symptoms. This relates to a crucial aspect of school-based deworming that is in need of urgent attention. Communication with targeted populations is poor, and health education materials are inadequate. As a result, the involvement of those being expected to swallow medications in the planning and implementation of programmes is minimal, raising a serious question when it comes to treating children. To expect pupils to consume tablets without the permission and support of their parents would not be possible in most parts or the world. Why should it be acceptable in Africa?

Certainly, for positive effects to occur from any kind of school-based deworming, it is necessary to ensure that the children targeted actually consume the tablets in the correct doses. Yet, on this crucial matter too, information is weak or non-existent from most locations in East Africa. Ethnographic fieldwork and examination of school registers in Uganda and Tanzania shows that school-based deworming treatment is almost invariably more successful in terms of drug consumption than mass drug administration to populations as a whole. Nonetheless, it usually falls well short of expectations and re-infection is common. In those places where there are indications of a decline in the prevalence and intensity of infection, sustained disease control will require the indefinite distribution of medications, with corresponding risks. Over time, drug resistance is probable. There are already worrying signs, even if conclusive evidence of it occurring in field settings for any of the targeted parasites in human populations remains absent at present. 
Whatever the purported merits of large-scale deworming, it is vital that independent biosocial surveillance is undertaken. At the moment, this rarely happens. Most of the scholarly research occurs in disciplinary silos, and some of it is affected by overly optimistic expectations. The fact that deworming drugs are widely available is a unique opportunity, but it is not a cheap fix for poverty or a 'magic bullet' to achieve health for all. Delivery of therapy in a sustained and appropriate manner requires a much more serious engagement with health system constraints, and local realities, as well as recognition that those in most need of treatment are likely to be both politically as well as economically marginal. There is no dispute about the need to treat people suffering from debilitating parasitic infections, but deworming delusions are counter-productive.

\section{Acknowledgments}

This research on deworming in Ugandan and Tanzanian schools is based on fieldwork funded by the Schistosomiasis Control Initiative, Imperial College, under the auspices of the Bill and Melinda Gates Foundation. Ethical clearance was passed by the ethics committee of Imperial College for surveillance and monitoring activities for the evaluation of national control programmes for control of NTDs. Separate ethical clearance applications were also passed by the Ugandan Ministry of Health and the Tanzanian Commission for Science and Technology (COSTECH). The authors are grateful to Alan Fenwick, the director of SCI, for supporting this research. Other staff at SCI have also been helpful, including Lynsey Blair, Fiona Fleming, Artemis Koukounari and Alice Norton. In Uganda, the authors are indebted to numerous staff from the Ministry of Health, including Narcis Kabatereine and Ambrose Onapa, as well as the district vector control officers Oneba Dickson, the late Nicholas Ogweng and Frederick Kadama. Useful assistance in the field was also provided by Emily Aldis, Andeevu Caesar, Rachel Flynn, Philip Goli, Ronald Iya, Stanley Bright Jhopacu, Vuzara Kalisto, Nstori Onen, Bono Ozunga, Nicola Peach, Georgie Pearson, Ruth Tushememereirwe and Albert Wutham. In Tanzania, the help of the following is much appreciated: Shumu, Juma, Mishy, Angela, Nasir, Suleiman and the late Kombo Iddi, as well as John Changalucha, Julie Hastings, the late Nicholas Lwambo, Ursuline Nyandindi, Anjela Shira and Polly Wingate-Saul. Finally, the authors are grateful to Grace Akello, Alex Aiken, Dina Balabanova, Chris Blattman, Paul Garner, Georgina Pearson, Katja Polman and Johannes Sommerfeld for critically commenting on earlier versions of this article.

\section{References}

Aiken, A., Davey, C., Hargreaves, J. \& Hayes, R. (2015) Re-analysis of health and educational impacts of a school-based deworming program in western Kenya: a pure replication. International Journal Epidemiology doi: 10.1093/ije/dyv127.

Albonico, M., Engels, D. \& Savioli, L. (2004) Monitoring drug efficacy and early detection of drug resistance in human soil-transmitted nematodes: a pressing public health agenda for helminth control. International Journal of Parasitology 34, 1205-1210.

Aldis, E. (2008) Gender, behaviour and schistosomiasis in northwest Uganda: questioning common assumptions. MSc dissertation, London School of Economics. 
Allen, T. \& Parker, M. (2012) Will increased funding for neglected tropical diseases really make poverty history? The Lancet 379(9821), 1097-1098.

Allotey, P., Reidpath, D. \& Pokhrel, S. (2010) Social science research in neglected tropical diseases 1: the on-going neglect in neglected tropical diseases. Health Research Policy and Systems $\mathbf{8}, 32$.

Amin, M. A. \& El Hussin, D. M. (2009) Challenges in prevention and control of schistosomiasis in the Sudan. Sudan Journal of Medical Science 4(1), 79-83.

Anderson, R. M., Truscott, J. E., Pullan, R. L., Brooker, S. J. \& Hollingsworth, T. D. (2013) How effective is school-based deworming for the community-wide control of soil-transmitted helminths? PLoS Neglected Tropical Diseases 7(2), e2027.

Baird, S., Hicks, J. H., Kremer, A. \& Miguel, E. (2015) Worms at work: long run impacts of a child health investment. Working Paper No. 21428, National Bureau of Economic Research. URL: http://www.nber.org/papers/w21428.

BBC (2015) More or Less. Worm Wars. Broadcast on BBC Radio 4 on Friday August $14^{\text {th }} 2015$. URL: http://www.bbc.co.uk/programmes/p02znr77.

Bethony, J., Brooker, S., Albonico, M., Geiger, S. M., Loukas, A., Diemert, D. \& Hotez, P. J. (2006) Soil-transmitted helminth infections: ascariasis, trichuriasis, and hookworm. The Lancet 367(9521), 1521-1532.

Blattman, C. (2015) 10 Things I Learned from the Trenches of the Worm Wars. URL: http:// chrisblattman.com/2015/07/24/the-10-things-i-learned-in-the-trenches-of-the-worm-wars/.

Bleakley, H. (2002) Disease and Development: Evidence from Hookworm Eradication in the American South. Report of the Rockefeller Sanitary Commission. URL: http://web.mit.edu/hoyt.

Bosley, S. (2015) New research debunks merits of global deworming programmes. The Guardian, July $23^{\text {rd }} 2015$.

Brooker, S., Hay, S. I., Issae, W., Hall, A., Charles, M. K., Lwambo, J. S. et al. (2001) Predicting the distribution of urinary schistosomiasis in Tanzania using satellite sensor data. Tropical Medicine \& International Health 6(12), 998-1007.

Brooker, S., Miguel, E. A., Moulin, S., Luoba, A. I., Bundy, D. A. P. \& Kremer, M. (2000) Epidemiology of single and multiple species of helminth infections among school children in Busia district, Kenya. East African Medical Journal 77(3), 157-161.

Bundy, D. (2011) New Reasons Why School-Based Deworming is Smart Development Policy. Education for Global Development, The World Bank. URL: http://blogs.worldbank.org/ education/rethinking-deworming.

Bundy, D. A. P. \& de Silva, N. R. (1998) Can we deworm this wormy world? British Medical Bulletin 54(2), 421-432.

Cavalli, A., Bamba, S. I., Traore, M. N., Boelaert, M., Coulibaly, Y., Polman, K. et al. (2010) Interactions between global health initiatives and country health systems: the case of a neglected tropical diseases control program in Mali. PLoS Neglected Tropical Diseases 4(8), e798.

Chan, L., Bundy, D. A. \& Kan, S. P. (1994) Aggregation and predisposition to Ascaris lumbricoides and Trichuris trichiuria at the familial level. Transactions Royal Society Tropical Medicine \& Hygiene 88, 46-48.

Clements, A. C., Bosqué-Oliva, E., Sacko, M., Landouré, A., Dembélé, R., Traoré, M. et al. (2009) A comparative study of the spatial distribution of schistosomiasis in Mali in 1984-1989 and 2004-2006. PLoS Neglected Tropical Diseases 3, e431.

Copenhagen Consensus (2013) Third Copenhagen Consensus: Infectious Disease Assessment. Section authored by Jamison, D., Jha, P, Laxminarayan, R. \& Ord, T. URL: http://www. copenhagenconsensus.com/publication/infectious-disease.

Colley, D. G., Bustinduy, A. L., Secor, W. E. \& King, C. H. (2014) Human schistosomiasis. The Lancet 383(9936), 2253-2264.

Correale, J. \& Farex, M. F. (2011) The impact of parasite infections on the course of multiple sclerosis. Journal Neuroimmunology 233, 6-11. 
Coulibaly, Y., Cavalli, A., van Dormael, M., Polman, K. \& Kegels, G. (2008) Programme activities: a major burden for district health systems? Tropical Medicine and International Health 13(12), $1430-1432$.

Davey, C., Aiken, A., Hayes, R. \& Hargreaves, J. (2015) Re-analysis of health and educational impacts of a school-based deworming programme in western Kenya: a statistical replication of a cluster quasi-randomized stepped-wedge trial. International Journal Epidemiology doi:10.1093/ ije/dyv128.

de Silva, N., Ahmed, B. N., Casapia, M., de Silva, H. J., Gyapong, J., Malecela, M. \& Pathmeswaran, A. (2015) Cochrane Reviews on deworming and the right to a healthy, wormfree life. PLoS Neglected Tropical Diseases 9(10), e0004203.

Dickson, R., Awasthi, S., Williamson, P., Demellweek, C. \& Garner, P. (2000) Effects of treatment for intestinal helminth infection on growth and cognitive performance in children: systematic review of randomised trials. British Medical Journal 320, 1697-1701.

Dunne, D. W., Butterworth, A. E., Fulford, A. J., Kariuki, H. C. \& Langley, J. G. (1992) Immunity after retreatment of human schistosomiasis: association between IgE antibodies to adult worm antigens and resistance to reinfection. European Journal of Immunology 22, $1483-1494$.

Economist (2015) How to debunk a study. The Economist, August 11th 2015.

Elkins, D. B., Haswell-Elkins, M. \& Anderson, R. M. (1998) The importance of host age and sex to patterns of reinfection with Ascaris lumbricoides following mass anthelmintic treatment in a South Indian fishing community. Parasitology 96, 171-184.

Elliot, A. M., Ndibazza, J., Mpairwe, H., Muhangi, L., Webb, E. L., Kizito, D. et al. (2011) Treatment with antihelminthics during pregnancy: what gains and what risks for the mother and child? Parasitology 138, 1499-1507.

Evans, D. (2015) Worm Wars: The Anthology. World Bank. URL: http://blogs.worldbank.org/ impactevaluations/worm-wars-anthology.

Evidence Action (2015) Worms Win, Kids Lose? Our Statement. $23^{\text {rd }}$ July 2015. URL: http://www. evidenceaction.org/blog-full/worms-win-kids-lose-our-statement.

Gates Foundation (2009) Progress Against Neglected Tropical Diseases. URL: https://docs. gatesfoundation.org/Documents/progress-against-neglected-tropical-diseases.pdf.

Gates Foundation (2014) Global Partners are Taking the "Neglect" out of "Neglected Tropical Diseases". Press Release and Statements. URL: http://www.gatesfoundation.org/Media-Center/ Press-Releases/2014/04/Global-Partners-Are-Taking-the-Neglect-out-of-Neglected-Tropical-Diseases.

Garner, P., Taylor-Robinson, D. \& Sachdev, H. S. (2015) Commentary: replication of influential trial helps international policy. International Journal of Epidemiology doi: 10.1093/ije/dyv131.

Geerts, S. \& Gryseels, B. (2000) Drug resistance in human helminths: current situation and lessons from livestock. Clinical Microbiology Reviews 13(2), 207-222.

Gertler, P. (2015) Good science gone wrong? The Berkeley Blog, 3rd August 2015. URL: http:// blogs.berkeley.edu/2015/08/03/good-science-gone-wrong/.

GiveWell (2015) New Deworming Reanalyses and Cochrane Review. URL: http://blog.givewell.org/ 2015/07/24/new-deworming-reanalyses-and-cochrane-review/.

Gray, D. J., McManua, D. P., Li, Y., Williams, G. M., Bergquist, R. \& Ross, A. G. (2010) Schistosomiasis elimination: lessons from the past guide the future. The Lancet Infectious Diseases 10, 733-736.

Grossman, J. \& Mackenzie, F. J. (2005) The Randomized Controlled Trial: gold standard, or merely standard? Perspectives in Biology and Medicine 48(4), 516-534.

Gryseels, B. (2006) Mass treatment for worms is mistaken. Financial Times, 23rd November 2006.

Gryseels, B., Mbaye, A., de Vlas, S. J., Stelma, F. F., Guissé, F., van Lieshout, L. et al. (2001) Are poor responses to praziquantel for the treatment of Schistosoma mansoni infections in Senegal due to resistance? An overview of the evidence. Tropical Medicine and International Health 6, 864-873. 
Gryseels, B., Polman, K., Clerinx, J. \& Kestens, L. (2006) Human schistosomiasis. The Lancet $\mathbf{3 6 8}$, $1106-1118$.

Guyatt, H. L., Brooker, S., Kihamia, C. M., Hall, A. \& Bundy, D. A. P. (2001) Evaluation of efficacy of school-based anthelmintic treatments against anaemia in children in the United Republic of Tanzania. Bulletin of the World Health Organization 79(8), 695-703.

Hagen, P., Blumenthal, U. J., Dunn, D., Simpson, A. J. G. \& Wilkins, A. H. (1991) Human IgE, IgG4 and resistance to reinfection with Schistosoma Haematobium. Nature 349, 243-245.

Halsey Rogers, F. (2005) Missing in Action: Teacher and Medical Provider Absence in Developing Countries. URL: http://econ.worldbank.org/external/default/main?theSitePK $=469382 \&$ content $\mathrm{MDK}=20661217$ \&menuPK $=476752$ \&page $\mathrm{PK}=64165401$ \&piPK $=64165026$.

Hastings, J. (2016) Rumours, riots and the rejection of mass drug administration for the treatment of schistosomiasis in Morogoro, Tanzania. Journal Biosocial Science 48(S1), S16-S39.

Hawkes, N. (2015) Evidence for spending millions on deworming schoolchildren is inadequate. British Medical Journal 351, h3952.

Hicks, J. H., Kremer, M. \& Miguel, E. (2015) Commentary: deworming externalities and schooling impacts in Kenya: a comment on Aiken et al. (2015) and Davey et al. (2015). International Journal of Epidemiology doi: 10.1093/ije/dyv129.

Humphreys, M. (2015) What Has Been Learned from the Deworming Replications: A Nonpartisan View. Columbia University, $18^{\text {th }}$ August 2015. URL: http://www.columbia.edu/ $\sim \mathrm{mh} 2245 / \mathrm{w} /$ worms.html.

Humphries, D., Nguyen, S., Boakye, D., Wilson, M. \& Cappello, M. (2012) The promise and pitfalls of mass drug administration to control intestinal helminth infections. Current Opinion Infectious Diseases 25(5), 584-589.

Jack, A. (2006) WHO in ground-breaking treatment drive. Financial Times, October $26^{\text {th }} 2006$.

Kabatereine, N. B., Ariho, C. \& Christensen, N. O. (1992) Schistosoma mansoni in Pakwach, Nebbi District, Uganda, 40 years after Nelson. Tropical Medicine and Parasitology 43(3), $162-166$.

Kabatereine, N. B., Brooker, S., Koukounari, A., Kazibwe, F., Tukahebwa, E. M., Fleming, F. M. et al. (2007) Impact of a national helminth control programme on infection and morbidity in Ugandan schoolchildren. Bulletin of the World Health Organization 85, 97-99.

Kabatereine, N. B., Kazibwe, F. \& Kemijumbi, J. (1996) Epidemiology of schistosomiasis in Kampala, Uganda. East African Medical Journal 73, 795-800.

Kabatereine, N. B., Malecela, M., Lado, M., Zaramba, S., Amiel, O. \& Kolaczinski, J. H. (2010) How to (or Not to) integrate vertical programmes for the control of major neglected tropical diseases in Sub-Saharan Africa. PLoS Neglected Tropical Diseases 4(6), e755.

Kababereine, N. B., Standley, C. J., Sousa-Figueiredo, J. C., Fleming, F. M., Stothard, J. R. et al. (2011) Integrated prevalence mapping of schistosomiasis, soil-transmitted helminthiasis and malaria in lakeside and island communities in Lake Victoria, Uganda. Parasites \& Vectors 4, e232.

Karanja, D. M. S., Hightower, A. W., Colley, D. G., Mwinzi, P. N. M., Galil, K., Andove, J. \& Secor, W. E. (2002) Resistance to reinfection with Schistosoma mansoni in occupationally exposed adults and effect of HIV-1 co-infection on susceptibility to schistosomiasis: a longitudinal study. The Lancet 360, 592-596.

Kenya National School-Based Deworming Programme (KNSDP) (2014) Year 2 report (April 2013-March 2014). URL: http://webcache.googleusercontent.com/search?q=cache: y-n9IeGk018J:https://ciff.org/documents/16/Kenya_National_SchoolBased_Deworming_Programme_ Year2_evaluation.pdf $+\& \mathrm{~cd}=1 \& \mathrm{hl}=\mathrm{en} \& \mathrm{ct}=\mathrm{clnk} \& \mathrm{gl}=\mathrm{uk}$.

Kremer, M. \& Miguel, E. (2007) The illusion of sustainability. Quarterly Journal of Economics 122(3), 1007-1065.

Kremer, M. \& Miguel, E. (2015) Understanding Deworming Impacts on Education. URL: http:// scholar.harvard.edu/files/kremer/files/deworming-summary_kremer-miguel_2015-07-24-clean.pdf. 
London Declaration on Neglected Tropical Diseases (2012) URL: http://unitingtocombatntds.org/ resource/london-declaration.

Mahmoud, A. \& Zerhouni, E. (2009) Neglected Tropical Diseases: moving beyond mass drug treatment to understanding the science. Health Affairs 28(6), 1726-1733.

Meheus, F., Rijal, S., Lutumba, P., Hendrickx, D. \& Boelaert, M. (2012) NTD control and health system strengthening. The Lancet 379, 2149-2150.

Miguel, E. \& Kremer, M. (2002) Why Don't People Take Their Medicine? Experimental Evidence from Kenya. URL: http://www.researchgate.net/publication/228602508_Why_Don't_People_ Take_Their_Medicine_Experimental_Evidence_from_Kenya.

Miguel, E. \& Kremer, M. (2004) Worms: identifying impacts on education and health in the presence of treatment externalities. Econometrica 72(1), 159-217.

Mohamad, G. (1993) The epidemiology of Schistosoma mansoni in the Gezira-Managil area of Sudan: impact of the Blue Nile Health Project. PhD dissertation, Department of Biological Anthropology, University of Cambridge.

Molyneux, D. H. \& Malecela, M. N. (2011) Neglected Tropical Diseases and the Millennium Development Goals - why the "other diseases" matter: reality versus rhetoric. Parasites \& Vectors 4, 234.

Molyneux, D., Malecela, M., Savioli, L., Fenwick, A. \& Hotez, P. (2012) Will increased funding for neglected tropical diseases really make poverty history - Authors' reply. The Lancet 379, 1098-1099.

Montresor, A., Addiss, D., Albonico, M., Ali, S. M., Ault, S. K., Gabrielli, A-F. et al. (2015) Methodological bias can lead the Cochrane collaboration to irrelevance in public health decision-making. PLoS Neglected Tropical Diseases 9(10), e0004165.

Mugono, M., Konje, E., Kuhn, S., Mpogoro, F. J., Morona, D. \& Mazigo, H. D. (2014) Intestinal schistosomiasis and geohelminths of Ukara Island, North-Western Tanzania: prevalence, intensity of infection and associated risk factors among school children. Parasites and Vectors 7, 612.

Muhumuza, S., Olsen, A., Katahoire, A. \& Nuwaha, F. (2013) Uptake of preventive treatment for intestinal schistosomiasis among school children in Jinja District, Uganda: a cross sectional study. PLoS One 8(5), e63438.

Muhumuza, S., Olsen, A., Katahoire, A. \& Nuwaha, F. (2015) Understanding low uptake of mass treatment for intestinal schistosomiasis among school children: a qualitative study in Jinja District, Uganda. Journal of Biosocial Science 47(4), 505-520.

Mwanga, J. R. (2005) Perceptions and practices on schistosomiasis among communities in Ukerewe District, Tanzania. Tanzania Health Research Bulletin 7(2), 55-61.

Nikolay, B., Mwandawiro, C. S., Kihara, J. H., Okoyo, C., Cano, J., Mwanje, M. T. et al. (2015) Understanding heterogeneity in the impact of national neglected tropical disease control programmes: evidence from school-based deworming in Kenya. PLoS Neglected Tropical Diseases 9(9), e0004108.

Odiere, M. R., Rawago, F. O., Ombok, M., Secor, W. E., Karanja, D. M. S., Mwinzi, P. N. M. et al. (2012) High prevalence of schistosomiasis in Mbita and its adjacent islands of Lake Victoria, western Kenya. Parasites \& Vectors 5, 278.

Odongo-Aginya, E. I., Grigull, L., Schweigmann, U., Loroni-Lakwo, T., Enrich, J. H. H., Gryseels, B. \& Doehring, E. (2002) High prevalence and morbidity of Schistosoma mansoni along the Albert Nile in Uganda. African Health Sciences 2(3), 99-106.

Ozunga, B. E. (2014) Is there any evidence to suggest that mass drug administration will control schistosomiasis among children? A case study of Northwest Uganda. MSc thesis in International Development and Humanitarian Emergencies, London School of Economics.

Parker, M. (1989) The effects of Schistosoma mansoni on female activity patterns and infant growth in Gezira Province, Sudan. DPhil, University of Oxford.

Parker, M. (1992) Re-assessing disability: the impact of schistosomal infection on daily activities among women in Gezira Province, Sudan. Social Science \& Medicine 35(7), 877-890. 
Parker, M. (1993) Bilharzia and the boys: questioning common assumptions. Social Science \& Medicine 37(4), 481-492.

Parker, M. \& Allen, T. (2011) 'Does Mass Drug Administration for the Integrated Treatment of Neglected Tropical Diseases Really Work? Assessing Evidence for the Control of Schistosomiasis and Soil-transmitted Helminths in Uganda'. Health Research Policy and Systems 9, 3.

Parker, M. \& Allen, T. (2013a) Will mass drug administration eliminate lymphatic filariasis? Evidence from northern coastal Tanzania. Journal of Biosocial Science 45, 517-545.

Parker, M. \& Allen, T. (2013b) Questioning ethics in global health. In MacClancy, J. \& Fuentes, A. (eds) Ethics in the Field: Contemporary Challenges. Berghahn Press, Oxford, pp. $24-41$.

Parker, M. \& Allen, T. (2014) De-politicizing parasites: reflections on attempts to control the control of neglected tropical diseases. Medical Anthropology 33(3), 223-239.

Parker, M., Allen, T. \& Hastings, J. (2008) Resisting control of neglected tropical diseases: dilemmas in the mass treatment of schistosomiasis and soil-transmitted helminths in north-west Uganda. Journal of Biosocial Science 40, 161-181.

Parker, M., Allen, T., Pearson, G., Peach, N., Flynn, R. \& Rees, N. (2012) Border parasites: schistosomiasis control among Uganda's fisherfolk. Journal of Eastern African Studies 6(1), 97-122.

Partnership for Child Development (1999) The cost of large-scale school health programmes which deliver anthelmintics to children in Ghana and Tanzania. Acta Tropica 73(2), 183-204.

Partnership for Child Development (2002) Heavy schistosomiasis associated with poor short-term memory and slower reaction times in Tanzanian schoolchildren. Tropical Medicine and International Health 7, 104-117.

Pearson, G. (2016) Low prevalence of intestinal schistosomiasis among fisherfolk living along the River Nile in northwestern Uganda: a biosocial investigation. Journal Biosocial Science 48(S1), S74-S91.

Pinot de Moira, A., Fulford, A. J. C., Kabatereine, N. B., Ouma, J. H., Booth, M. \& Dunne, D. W. (2010) Analysis of complex patterns of human exposure and immunity to schistosomiasis mansoni: the influence of age, sex, ethnicity and IgE. PLoS Neglected Tropical Diseases 4, e820.

Quinnel, R. J., Slater, A. F., Tighe, P., Walsh, E. A., Keymer, A. E. \& Pritchard, D. I. (1993) Reinfection with hookworm after chemotherapy in Papua New Guinea. Parasitology 106, 379-385.

Reisz, M. (2013) Unwanted side-effects. Times Higher Education, 30 ${ }^{\text {th }}$ May 2013.

Samsky, A. (2012) Scientific sovereignty: how international drug donation programs reshape health, disease, and the state. Cultural Anthropology 27(2), 310-332.

Satti, M. Z., Lind, P., Vennervald, B. J., Sulaiman, S. M., Daffalla, A. A. \& Ghalib, H. W. (1996) Specific immunoglobulin measurements related to exposure and resistance to Schistosoma mansoni infection in Sudanese canal cleaners. Clinical and Experimental Immunology 106, 45-54.

Simonsen, P. E., Derua, Y. A., Kisinza, W. N., Magesa, S. M., Malecela, M. N. \& Pedersen, E. M. (2013) Lymphatic filariasis control in Tanzania: effect of six rounds of mass drug administration with ivermectin and albendazole on infection and transmission. BMC Infectious Diseases 13, 335.

Stothard, R., Khamis, A., Khamis, I. S., Neo, C. H. E., Wei, I. \& Rollinson, D. (2016) Health education and the control of urogenital schistosomiasis: assessing the impact of the 'Juma $\mathrm{Na}$ Kichocho' comic-strip medical booklet in Zanzibar. Journal Biosocial Science 48(S1), S40-S55.

Taylor-Robinson, D. C., Maayan, N., Soares-Weiser, K., Donegan, S. \& Garner, P. (2012) Deworming drugs for soil-transmitted intestinal worms in children: effects on nutritional indicators, haemoglobin and school performance. Cochrane Database Systematic Review. $11^{\text {th }}$ July, 7:CD000371, doi: 10.1002/14651858.CD000371.pub4.

Taylor-Robinson, D. C., Maayan, N., Soares-Weiser, K., Donegan, S. \& Garner, P. (2015) Deworming drugs for soil-transmitted intestinal worms in children: effects on nutritional indicators, haemoglobin, and school performance. Cochrane Database Systematic Review. 23 ${ }^{\text {rd }}$ July 23, 7:CD000371, doi: 10.1002/14651858.CD000371.pub6. 
Tchuente, T. L.-A., Kabatereine, N., Karanja, D. \& Dennis, E. (2006) Mass treatment for worms is the correct way forward. Financial Times, $16^{\text {th }}$ November 2006.

Utzinger, J., N'Goran, E. K., Caffrey, C. R. \& Keiser, J. (2011) From innovation to application: socio-ecological context, diagnostics, drugs and integrated control of schistosomiasis. Acta Tropica 1205, S121-S137.

Vereecken, K., Naus, C. W. A., Polman, K., Scott, J. T., Diop, M., Gryseels, B. \& Kestens, L. (2007) Associations between specific antibody responses and resistance to reinfection in a Senegalese population recently exposed to Schistosoma mansoni. Tropical. Medicine and International Health 12(3), 431-444.

Waghorn, T. S., Leathwick, D. M., Rhodes, A. P., Lawrence, K. E., Jackson, R., Pomroy, W. E. et al. (2006) Prevalence of anthelmintic resistance on sheep farms in New Zealand. New Zealand Veterinary Journal 54(6), 271-277.

Walter, K., Fulford, A. J. C., Mcbeath, R., Joseph, S., Jones, F. M., Kariuki, H. C. et al. (2006) Increased human IgE induced by killing schistosoma mansoni in vivo is associated with pretreatment Th2 cytokine responsiveness to worm antigens. Journal of Immunology 177(8), $5490-5498$.

Wingate-Saul, P. \& Shira, A. (2008) Part 2: report on the distribution of praziquantel to school children and adults in Ukerewe District, Tanzania in October 2007. In Parker, M. (ed.) Monitoring and Evaluating the National Schistosomiasis and Soil Transmitted Helminths Control Programme, Tanzania. Commission for Science and Technology, Tanzania.

WHO (1987) Atlas of Global Distribution of Schistosomiasis. URL: http://www.who.int/ schistsomiasis/epidemiology/en/uganda.pdf.

WHO (2001) World Health Assembly Resolution 54.19. WHO, Geneva.

WHO (2003) School Deworming at a Glance. WHO, Geneva.

WHO (2005a) Deworming for Health and Development. Report of the third Global Meeting of the Partners for Parasite Control. WHO, Geneva.

WHO (2005b) Deworming: The Millennium Development Goals. Strategy Development and Monitoring for Parasitic Diseases and Vector Control Team. WHO, Geneva.

WHO (2007) Global Plan to Combat Neglected Tropical Diseases 2008-2015. WHO, Geneva URL: http://apps.who.int/iris/bitstream/10665/69708/1/WHO_CDS_NTD_2007.3_eng.pdf.

WHO (2010) Working to Overcome the Global Impact of Neglected Tropical Diseases. First WHO report on neglected tropical diseases. WHO, Geneva.

WHO (2015) WHO Advisory Body Upholds Continued Deworming of Children Against Soil-Transmitted Helminthiases. URL: http://www.who.int/neglected_diseases/news/updatedeworming-children/en/.

WHO (2016) Neglected Tropical Diseases. URL: http://www.who.int/neglected_diseases/diseases/en/. Yamey, G. (2009) The unsung hero of neglected tropical diseases: interview with Narcis Kabatereine. PLoS Neglected Tropical Diseases 3(12), e546.

Zhang, Y., Koukounari, A., Kabatereine, N., Fleming, F., Kazibwe, F., Tukahebwa, E. et al. (2007) Parasitological impact of 2-year preventive chemotherapy on schistosomiasis and soiltransmitted helminthiasis in Uganda. BMC Medicine 5, 27. 